\title{
Why organizations fail to share knowledge: An empirical investigation and opportunities for improvement
}

\section{Structured abstract:}

Purpose - This paper explores critical failure factors (CFFs) in the context of knowledge sharing. It provides further insights into what can cause knowledge sharing failures, inflexible knowledge sharing strategies and ineffective knowledge sharing mechanisms. It also examines how practitioners can reduce or even mitigate such dysfunctions.

Design/methodology/approach - A case-based inductive approach was conducted. Data was collected from two studies applying mixed methods. The first data set included nine in-depth, semi-structured interviews with highly skilled personnel from an Aerospace and Defense organization. The second data source included 375 successfully completed questionnaires from participants employed at the same organization.

Findings - The paper identifies six CFFs with an impact on knowledge sharing. It also reveals that managing organizational ignorance can play a key role in generating new knowledge and averting failure. Study findings provide insights into the importance of identifying these failures when sharing knowledge and propose relevant mitigation strategies.

Originality/value - This paper identifies a range of empirically validated CFFs that complement the extant work on the complexity of knowledge sharing and have hitherto not been seen in the literature. It also provides a more nuanced understanding of why both organizations and their people often fail to share knowledge by exploring the role of organizational ignorance.

Keywords: knowledge sharing, critical failure factors (CFFs), organizational ignorance, mixed methods, aerospace and defense industry

Article Type: Research paper 


\section{Introduction}

Practitioners often neglect the study of failure when investigating factors that can help to improve organizational performance (Storey and Barnett, 2000). Efforts mainly focus on success, which is commonly interpreted as innovativeness (e.g., Davenport and Prusak, 1998), effectiveness and efficiency (e.g., Argote and Ingram, 2000) as well as customer responsiveness (e.g., Darr et al., 1995). Success, however, can occur from ad-hoc situations or coincidence, and, if looked at in isolation, it can restrict organizations from achieving their full potential for a number of reasons, such as inconsistent application, misuse and misinterpretation (Chong, 2006). This study explores organizational failure and seeks to better understand how certain failure factors might affect knowledge sharing effectiveness. We focus on critical failure factors (CFFs) as organizations that are able to identify such factors can reduce the damage caused by knowledge deficient situations (du Plessis, 2007).

Reviewing the extant knowledge sharing literature, CFFs associated with knowledge trajectories (i.e. in relation to a stated knowledge goal over time) are not adequately identified or discussed at either an organizational or individual level. A number of scholars (e.g., Braganza and Möllenkramer, 2002; Fontaine and Lesser, 2002; Malhotra, 2004) have previously looked at the need to minimize failures during the implementation of knowledge sharing, but they have not explicitly identified specific constructs affecting this process. Cannon and Edmondson (2005) have noted the need for organizations to explore alternative routes to knowledge sharing, to minimize causes of failures during the process, but their study neither ascertains these failures, nor identifies their causes. Revealing CFFs and their antecedents when organizations share knowledge can help them to become aware of potential knowledge gaps that may persist within their structures. Further, it might enable them to predict and avert dysfunctional knowledge sharing scenarios and prevent them from escalating into dangerous and less manageable issues. 
To prevent situations of knowledge deficit, we explore CFFs which dysfunction knowledge sharing. The aim of this study is to gain further insights into what can cause knowledge sharing failures, inflexible knowledge sharing strategies and ineffective knowledge sharing mechanisms, and how practitioners can reduce or even mitigate such dysfunctions. Our study contributes to the Knowledge Management (KM) literature by identifying a range of empirically validated CFFs with an impact on knowledge sharing. Furthermore, we provide a more nuanced understanding of ignorance, as the lack of inadequate or even false knowledge, looking at how it may be linked to the mitigation of failures and the complexity of managing failure-prone situations. These findings develop organization study theory, which traditionally views failures as resulting from managerial misconduct or a misleading behavior, by also considering subordinates' actions and wider organizational characteristics, processes and structures.

The remainder of the paper is structured as follows: the next section offers a review of the current literature on organizational failure, knowledge sharing and ignorance, as well as explaining the rationale behind the CFFs explored in this study. The research methodology, along with details of the studies conducted and their results are outlined in the third section. The fourth section sets out the discussion and provides implications for both theory and practice, while the fifth and final section concludes the main study outcomes.

\section{Literature review and study research propositions}

\subsection{Organizational failure and CFFs}

Although organizational failure is often not directly identified by organizations in practice, it has been increasingly acknowledged within organization studies (Chua and Lam, 2005; Mellahi et al., 2002; Peters, 1987). Two perspectives emerge from this broad area of study (Mellahi and Wilkinson, 2004). The first adopts an external focus, in which: "[...] managers 
are constrained by exogenous industrial and environmental constraints leaving them with little real strategic choice" (Mellahi and Wilkinson, 2004: 21). In this view, organizational failure is depicted as an inevitable consequence of the process of 'natural selection' and 'survival of the fittest' (Amankwah-Amoah, 2016, p. 3389). Consequently, failing firms are seen as the 'unfortunate' victims of external circumstances, the failures of which do not necessarily imply management ineffectiveness or inefficiency. An internal perspective, however, associates failure with managerial behavior, as: "[...] managers are the principal decision makers of the firm and, consequently, their actions and perceptions are the fundamental cause of organizational failure" (Mellahi and Wilkinson, 2004: 21).

The study of organization failure is understandably hindered by managerial worries about the absence of success and a desire not to be associated with organizational failures (Edmondson, 2011). Further, management tends to limit or control access to key people during failure, particularly if it feels it has something to hide or that research could compromise the survivability of the organization (Mellahi, 2005). Organizational failures remain an 'organizational taboo' (Chua and Lam, 2005), even though long-term success requires organizations to experiment with trying out new practices to avoid plausible failures. Organizations intentionally lacking the appropriate culture to study failure may miss out on opportunities to reveal learning opportunities (Sitkin, 1992). Besides, Amankwah-Amoah (2016, p. 3394) highlights the inherent benefits of learning from other organizations' failures to not only improve their own competitiveness, but also to avoid falling into the same traps. However, there is a lack of consensus among practitioners over how organizations can benefit from others' failure without exposing themselves to any contagion effects.

Organizational failure is often seen as a crisis or a more gradual decline without distinguishing between the two (Starbuck et al., 1978). However, success can often come about from ad-hoc situations or coincidence, and if it is aspirational in nature, organizations are rarely 
able to determine objectively how far from success they are. These different perspectives on the causes and antecedents of organizational failure, also lead to definitional confusion. It is habitually referred to as the opposite of a successful situation, which is the default position for an organization to prosper without reference to failure (Chua and Lam, 2005). Further, it is seen to be caused by a sequence, combination or lack of critical success/failure factors (Belassi and Tukel, 1996). However, this conceptualization is often misleading, as failures cannot be clearly distinguished from success factors. Conflating and using these two opposing events or conditions interchangeably, or seeing one as the absence of the other, can lead to conflicting outcomes, as organizational success is generally more frequently documented or publicized (Jafari et al., 2009). Instead, the efforts put into the investigation of failure factors and their roots are rarely as rigorous and usually undersampled (Denrell, 2003).

CFFs have been identified and explored in a number of different areas of literature; Enterprise Resource Planning implementation (e.g., Ganesh and Mehta, 2010), Information Systems projects (e.g., Yeo, 2002), Continuous Improvement in manufacturing (e.g., Laureani and Antony, 2012) and more generally in project management (e.g., Belassi and Tukel, 1996); but the literature is more limited in relation to knowledge sharing. Drawing on this literature and Flowers (1997), we see CFFs as the organizational conditions or events that, when present, mean a management process does not operate as expected and its overall performance is suboptimal.

\subsection{Knowledge sharing and CFFs}

The role of knowledge as a resource of organizational competitiveness has been widely noted in both theory and practice (Madsen and Desai, 2010). Organizations knowing (which found to be knowledgeable of) how to effectively share the knowledge they possess or continually acquire new knowledge often gain sustainable competitive advantage. Although there is a lack of clear consensus on the precise definition of knowledge sharing, mainly because the content 
varies in terms of the organizational knowledge to be shared (e.g., know-why; know-with; know-when), it is often described as "the provision or receipt of task information, know-how and feedback regarding a product or procedure" (Cummings, 2004, p. 352). The usefulness of knowledge sharing depends on its purpose (i.e., contribution, relatedness, context conditional) and it usually takes place between two or more individuals, organizational teams and divisions, either within or outside an organization, following either, or both, formal or informal procedures (Alavi and Leidner, 2001; Argote and Ingram, 2000; Cummings, 2004; Dahlin et al, 2005; Hardy et al., 2003; Tsai, 2001).

Despite evidence to suggest that organization failure is more important than success (Nonaka and Takeuchi, 1995; Sitkin, 1992), extant KM literature lacks sufficient empirical research around exploring factors associated with knowledge sharing failures. Only recently, a narrow body of scholarly research demonstrates failure factors, which are associated with human capital decay in knowledge sharing activities. Akhavan and Pezeshkan (2014) and Tooranloo et al. (2018) are the first to provide a comprehensive review of KM CFFs and identify a list of failures associated with technological, project management and cultural aspects. Yet, their findings are not directly applicable to knowledge sharing differences. Chua and Lam (2005) show that failures in sharing knowledge are because of cultural factors, such as a knowledge-hoarding mentality and a lack of trust. Besides, Tooranloo et al. (2018, p. 191) identify the lack of a knowledge-sharing management orientation as an important failure factor. Further, the lack of knowledge sharing because of knowledge speculation is also seen amongst the key failure factors within the KM literature (Akhavan and Pezeshkan, 2014).

Organizational knowledge generated from failures is found to depreciate more slowly than that acquired from success (Madsen and Desai, 2010; Tax and Brown, 1998). As a more context-specific conceptualization of CFFs, Davenport et al. (1998) show that organizational failures might occur due to the lack of growth in the volume of knowledge content and usage, 
as well as the lack of clearly defined financial returns. A lack of managerial awareness of CFFs can endanger management knowledge projects and waste finite organizational resources. Understanding these factors can inform managers of poorly performing aspects of their processes and also reveal issues that have been overlooked or intentionally distorted. Therefore, evaluating the CFFs affecting knowledge sharing in organizations and planning to resolve them "can provide appropriate conditions for the implementation of $K M$ in an organization" (Tooranloo et al., 2018, p. 199).

The risks of conflating CSFs and CFFs prevent organizations from exploring alternative routes to knowledge enhancement as well as focusing on the identification of problems and probable causes of failure (Cannon and Edmondson, 2005). This need should be taken in the context of estimates showing that eighty percent of knowledge sharing projects have failed (Tooranloo et al., 2018, p.188). Explicit reporting of knowledge sharing failures is limited for the reasons outlined in the discussion of organizational failure; however, the costs of poor knowledge sharing practices have been identified in the practitioner literature. Many of these costs relate to wasted productivity in terms of time spent looking for information, being required to access multiple Knowledge Management Systems (KMSs), missing critical information and poorly informed decision making (Gallivan, et al., 2003; Schubmehl and Vesset, 2014). It is important for an organization therefore to understand different obstacles of knowledge flow that can have an impact on implementing and maintaining effective KM practices.

The under-researched nature of CFFs in KM leads to the distillation of our first research proposition, from which we generate our first contribution to the literature.

Research Proposition 1: What CFFs dysfunction knowledge sharing effectiveness?

\subsection{The role of ignorance in knowledge sharing}


As discussed above, an internally focused perspective of organizational failure, stemming from organization studies (OS) and organizational psychology (OP) literature, prioritizes managerial actions and perceptions as the fundamental cause of organizational failure (Mellahi and Wilkinson, 2004). Following this approach, the interrelation between knowledge sharing and organizational ignorance has been found to play a key role in generating new knowledge and averting failure (Bakonyi, 2018). Although the concept of managing ignorance is acknowledged in a number of other fields such as sociology, psychology and public choice theory, it has only recently started to gain wider attention (Gross and McGoey, 2015) and still appears rather nascent in organization and KM studies (Chia and Holt, 2007; Roberts, 2013).

According to Roberts (2013, p. 226) "ignorance may be used in various ways, including: to preserve stability and working practices, to economize on cognitive resources through specialization, and to stimulate innovation". Extant KM literature sees ignorance as 'uncertainty in terms of received knowledge', 'ambiguity in perceived knowledge' and 'irrelevant knowledge with inappropriate flow and stream' as detrimental factors to a company's operations (Akhavan and Pezeshkan, 2014; Tooranloo et al., 2018). It is often found to be cited as a type of knowledge deficiency that leads to a number of knowledge-processing problems including uncertainty, complexity, ambiguity and equivocality (Zack, 2000). From a sociological point of view, the role of ignorance has been closely studied by Bakonyi (2018) who argues that the quest for knowledge is embedded in the managerial rationality of interventions, which structures the developmental knowledge field and, thereby, generates ignorance. Specifically, she states that knowledge generation and transfer is intertwined with and enabled by ignorance, and in particular omission, silence, secrecy and vagueness. This viewpoint that ignorance is enacted through and functions in conjunction with knowledge (Taussig, 1999) opens up new ways of addressing organizational failure, from making better sense of existing knowledge to recognizing that there is always much more to learn. 
Drawing on existing definitions, we see organizational ignorance as the lack of employees' awareness about matters related to organizational knowledge stock (e.g., existing know-how) as well as other organizational characteristics (e.g., available tools and existing processes) rather than (just) the inability to understand. Organizations, which habitually fail to update employee knowledge, demonstrate a poor understanding of the external environment, resource misallocation, and misdirection of managerial attention (Amankwah-Amoah, 2016). It may also negatively affect employees' intention to share knowledge, thus leading to poor decision-making and communication in organizations (Israilidis et al., 2015). Hence, greater emphasis is necessary in 'challenging current knowledge; (unlearning); '[developing] strategies that explore and nurture their capacity to expect the unexpected'; and 'allowing members of the organization to expose their ignorance without fear of ridicule or prejudice' (Roberts, 2013, p. 230).

Building on the OS theory and the need to explore alternative routes to knowledge sharing improvement (Cannon and Edmondson, 2005), we look at how managing organizational ignorance is linked to the mitigation of failures. This, in turn, can also uncover the hidden ramifications of ignorance and help organizations to become aware of potential knowledge gaps that may persist within their structures. At the same time, it enables them to predict and avert dysfunctional KM scenarios or prevent them from escalating into dangerous and less manageable issues. This synthesis of the literature results in our second proposition:

Research Proposition 2: What is the relationship between organizational ignorance and knowledge sharing CFFs.

\section{Methodology}

\subsection{The research context}


A mixed-method approach was followed, incorporating a combination of qualitative and quantitative data into a single case study (Tashakkori and Teddlie, 1998). This approach aims to generate rich insights into participants' viewpoints and collect more focused data on the phenomenon (Patton, 2002). We selected an organization in the Aerospace and Defense industry as it has been acknowledged amongst the most knowledge-intensive sectors (Pinelli et al., 1997; Watson and Griffin, 2014). The construction and implementation of aerospace systems requires managing complexity, new knowledge implementation, significant and regular day-to-day interactions involving knowledge exchange and trust, as well as knowledge transferability by experts in the field. Adopting a single case study approach allowed us to delve deeply into the organization and provided a rich context in which to study knowledge sharing. The selected organization employs over 80,000 employees across the globe and has an annual turnover of around $£ 18$ billion.

\subsection{Study 1}

The first study is qualitative in nature and our aim was to (i) build theory by observing real structures, events and behaviors, which have not been extensively investigated in the past (Schein, 1987; Weber, 1947) and (ii) sought to understand factors that may restrict an organization from achieving its full potential. To ensure rigor in the qualitative research process we followed the oft-used five-stage research process model, i.e., research question definition, instrument development, data gathering, analysis and dissemination (Stuart et al., 2002; Voss et al., 2002; Yin, 2003).

\subsubsection{Data collection and analysis}

Our primary data source for this study (Study 1) was nine in-depth, semi-structured, interviews with highly skilled personnel from the organization, to collect appropriate information to explore failures when organizations share knowledge. The sampling was purposeful and participants were selected based on the following criteria: (i) they are senior executives and 
line managers at their organizations; (ii) they have all been engaged in KM projects; (iii) they work closely with other colleagues on tasks that require collaboration. The majority of the participants were males (eight males and one female), with an average age of 40.5 years old and had worked at the organization for an average of around 6 years.

Although a set of thirteen well-defined questions were initially designed, there was flexibility inherent in them via the extent of probing and question order. Prompts were also used to ensure that interviewees explore the main questions sufficiently. The interview protocol drew on Connelly and Kelloway (2003) and included questions to ascertain what inhibits the effectiveness of knowledge sharing, which factors are critical when knowledge is shared in the workplace and to elicit information regarding the interviewees' awareness of existing infrastructure, processes, networks and reward mechanisms for those who share knowledge. A number of sub-questions for further probing were also included in the study instrument. Each interview lasted around 45 minutes and all interviews were digitally recorded, after receiving the consent of the interviewees, and then transcribed. Inter coder reliability was achieved by multiple coding of the interviews by the research team using ATLAS.ti. Open coding involved developing new themes from the data.

\subsubsection{Study 1 findings}

The interview data revealed a number of areas that can act to inhibit knowledge sharing at both individual and organizational levels and this resulted in the identification of six knowledge sharing CFFs: (1) staff churn; (2), limited time availability; (3) unclear knowledge sharing goals; (4) lack of perceived encouragement; (5) ill-formalized knowledge sharing processes; (6) low quality training. Additionally, organizational ignorance was also acknowledged as a powerful indicator, which, if appropriately managed, can mitigate the magnitude of the failure. The key findings from Study 1 are briefly discussed below, along with indicative and illustrative quotations from the data. 


\section{Staff churn}

Given the aforementioned average age of employees, who are expected to leave the organization shortly, staff churn is one of the biggest challenges faced by the organization in the coming years and has the potential to engender a lack of innovation and creativity. The participants discussed how employees tended to follow existing ways of working, replicating these routines, without being open to considering different practices.

"People do not get used to think in an innovative way. They prefer to usually copy and use others knowledge instead of being creative by themselves".

\section{Limited time availability}

The study findings indicated that there is an inherent trade-off between the time taken to engage in $\mathrm{KM}$ activities and the benefits they can derive from such engagement. In addition, there is the limited amount of time required for employees to share the organizational knowledge they possess prevents them from participating in such activities. This time issue was also reflected in the attitudes expressed by the majority of interviewees regarding their willingness to share organizational knowledge.

"Can use up a lot of time with little immediate visible benefit. Detracts from the milestone achievement upon which we all as individuals are measured";

"Could waste people's time by continual interruptions for people trying to determine if they know something that they do not".

\section{Unclear knowledge sharing goals}

It was evident that employees may not derive the full benefits of knowledge sharing due to the lack of clear goals, the complex overall structure of reporting any lessons-learnt and the bureaucratic communications methods used within the organization.

"There is too much conflicting information sometimes. Senior management also like to do their own thing";

"We need a better way to track and share lessons learned. There is very little downside to sharing knowledge other than it might be misunderstood if it is just in a quick written form (i.e., always good to see if actual person / group with the knowledge can be available when needed for details)". 


\section{Lack of perceived encouragement}

The majority of the interviewees noted the lack of encouragement and/or suitable reward mechanisms and therefore could not achieve effective knowledge sharing. There was a consensus among participants that managerial direction in this area was often found to be missing. The study clearly indicated that this dysfunctional mismatch was found between highlevel (often abstract) knowledge sharing goals and the actions of lower-level managers at the practice level.

"Knowledge Sharing is viewed by management as possible waste of time and lack of task focus".

\section{Ill-formalized knowledge sharing processes}

The study itself was partly prompted by the organization's interest in whether their own intranet systems were being used effectively by their employees to share knowledge. The majority of participants highlighted that, despite the existence of files stored in the intranet, they were not comfortable undertaking tasks without frequent referrals to printed documentation. In situations where new knowledge was generated, employees had to rely on hard copies due to the limitation of existing IT infrastructure. However, given that most of the material was uploaded centrally, participants were often found to be unaware of the new knowledge being generated. It was also clear that documentation processes, as well as knowledge sharing processes needed to be formalized and reviewed regularly. This would enable management buy-in, facilitate knowledge sharing, and avoid any inefficiency or disruption to the smooth running of the organization's operations.

"Is it vetted (i.e., is the knowledge correct or are you getting bad data)? Hard to find the right data at the right time (too much or not enough)";

"Finding examples of similar work is the quickest way to find the people ("who put this together?" usually leads to a good contact). It would be a tremendous knowledge sharing benefit if there were more company-wide searchable databases for Proposals, Contract Deliverables, Engineering Design Reviews, and Program review materials along with point-of-contact information that were universally accessible. Would also be good to have a rating system (1 to 5 stars) to tap into the "wisdom of crowds".". 


\section{Low quality training}

In this study, most of the training programs provided appeared not to be directly focused on problems or knowledge sharing issues that managers were facing in the organization. The quality of training that employees had received for implementing knowledge sharing was found to be either average or poor across the organization.

"I think we place a lot of emphasis on the theoretical aspects of what we're trying to do. There tends to be a lack of emphasis on the how in training. You don't tend to get a sort of real-life demonstration of actually somebody who is in a situation doing the thing”;

"I think there is a lack of training delivered to middle managers".

\section{Organizational ignorance}

The focus of our study is on knowledge sharing and the organizational mechanisms that are designed and implemented to facilitate this. Therefore, we identified aspects of the employees' lack of awareness about matters related to organizational knowledge stock, rather than the inability to perform certain job-related tasks, which would be the focus of a skills- or competency-based study. Despite the existence of different reward mechanisms across the business, many of the participants were unaware of their presence and few seemed to understand how they worked. There was also clear evidence that employees were ignorant of the necessity to follow a common reporting structure for documenting lessons learned. Such ignorance resulted in knowledge deficiencies and missing key opportunities for improvement. The participants also felt that ignorance can easily build up due to training cutbacks and if the quality of training provision was low.

"There are no real mechanisms for rewarding any knowledge sharing. I already do work for parts of the organization other than my business line, and I am effectively doing this work out the goodness of my heart";

"There isn't any database of perhaps Learning from Experience, things that tell people what's gone right, what's gone wrong. There isn't anywhere that pulls our knowledge together";

"I think a lot of us struggle with identifying what Knowledge Sharing tools we use, because we're not aware of any specific Knowledge Sharing tools"; 
"I'm not aware of any knowledge sharing tools. I know the business had people who were looking at Knowledge Management but no idea how they went about it. No idea what tools they used or what tools were available. The only tools that I really use are my own eyeballs".

\subsection{Study 2}

Although the qualitative research interviews elicited rich responses from the participants' views on knowledge sharing, we recognized the limitations of the interview method in terms of the numbers of participants. Therefore, additional data was collected through a web-based survey that was e-mailed to potential participants. The thematic based findings of Study 1 led us to develop single-item self-report scales. This was to achieve greater breadth across the organization and also develop further insights into the complexity of knowledge sharing and what might inhibit its effectiveness. The design also included a number of open-ended questions to allow for a further elaboration of the participants' perceptions towards CFFs.

\subsubsection{Sample and procedure}

Prior to their participation, all potential participants were informed about the scope of the study and ensured anonymity and confidentiality. Only those who declared their agreement were eligible to participate in this study. Overall, 375 questionnaires were successfully completed and returned, out of 1000 sent out, giving a sufficient return rate of 37,5\%. Among the respondents, $85,1 \%$ were males, reflecting the gender gap in this sector (UK Department for Business, Energy and Industrial Strategy, 2018). Around half of the participants surveyed $(47,1 \%)$ were over the age of fifty-one, with the majority of these $(81,3 \%)$ being over fortyone years old. In addition, $68,5 \%$ were found to have worked for the organization for more than ten years, with only $3 \%$ joining less than one year prior. The survey respondents reported a broad range of experience including, directors (23,3\%), engineering authorities $(9,3 \%)$, commercial managers $(2,3 \%)$, project managers $(23,3 \%)$, business leaders $(4,7 \%)$ and senior planning managers $(37,1 \%)$.

\subsubsection{Measures}


To explore the type of codified knowledge used by employees in their daily routines tasks and activities we have drawn on Hara and Hew's (2007) framework of knowledge types. The study participants were asked to select between certain types of knowledge materials (e.g., guides, handbooks, templates, training materials) that they used and shared in the performance of their work tasks and activities. They were also asked to indicate when they make use of these knowledge materials (e.g., when they set up a new project; act as assessors or perform phase reviews) as well as the frequency they made use of the Intranet (e.g., on a daily, weekly, or a monthly basis).

For the single self-reported scales study participants were asked to indicate on a fivepoint Likert scale, ranging from 1) strongly disagree to 5) strongly agree, their perceptions towards the CCFs identified from the qualitative analysis. Examples, of single-items include: "I am not given enough time to share knowledge"; "Insufficient training is provided to share knowledge" and "Knowledge sharing processes are ill-formalized".

Control variables: We also controlled for four demographic variables; gender; age, organizational tenure and hierarchical level within the organization.

\subsubsection{Analysis}

Three types of data were collected from Study 2; (i) rich qualitative data, obtained through open-ended questions; (ii) the frequency of responses for the use of codified knowledge, the types of the materials used/in use, the use of intranet as well as the employees' perception towards the implementation of the new technology and (iii) quantitative data regarding the perceived quality of the training; the applicability and the effectiveness of knowledge sharing systems; the time provided to employees to share knowledge; and the perceived encouragement by their line manager to share knowledge, among others.

The first set of qualitative data was analyzed in three steps, as per Miles and Huberman (1994). We initially identified first order constructs using participants' answers before adopting 
an open coding approach (i.e. not using a pre-selected list of codes) to synthesize these into second order, thematically based, constructs that represent a series of relevant and focused CFFs. The second and third set of data was analyzed with SPSS using frequencies and correlations.

\subsubsection{Study 2 findings}

\subsubsection{Qualitative data}

The survey findings not only confirmed the six previously identified CFFs affecting knowledge sharing, but also provided us with a broader understanding of the rationale behind them along with associated challenges. Table 1 provides a summary of the qualitative findings derived from Study 2. Further analysis on how CFFs were portrayed as determined from the data is given below:

[Place Table 1 around here]

\section{Staff churn and closed mindset}

Participants identified that staff diversity caused by high levels of churn is linked to how knowledge is shared within the organization. In particular, given the different experience levels and average age of employees within the organization, they discussed the varying extent to which employees share knowledge, are knowledgeable about not only the significance of knowledge sharing itself, but also about the available tools, processes and mechanisms which facilitate knowledge sharing within the organization. Further, the aging workforce, exhibiting closed-minded characteristics, operates at a distance from knowledge sharing activities, as well as being unaware of not only the existence of the available KM facilitation tools, but also of the importance of knowledge sharing activities per se.

Limited time availability and the averseness to share knowledge

The study results confirmed that time is crucial for the effectiveness of knowledge sharing. The participants stated that the time needed to devote to sharing knowledge with their colleagues is 
limited, and that it prevents them from participating in knowledge sharing activities, especially when they are asked to accomplish tasks within predefined time constraints. The participants also stated that they either ignored or were unaware of the appropriate process or processes, as well as the available tools, which can help to share knowledge efficiently.

\section{Unclear knowledge sharing goals and task ambiguity}

The survey findings show that employees often experience ambiguity when they are engaged in knowledge sharing activities. They do not receive clear information from their line manager about the knowledge to be shared, to whom and to what extent. This confusion leads them to perceive the process itself as inconsistent. They also stated that they often ignored or were not aware of what knowledge needs to be shared. Perhaps more damaging, is that they often perceive the quality of knowledge shared in various organizational events as questionable, obsolete or misleading, making them feel confused about the organizational intentions to share knowledge.

\section{Lack of perceived encouragement and the feeling of being disenfranchised}

The study findings indicated that participants who received active encouragement from their line managers to share knowledge were the minority in the study. In addition, the study participants indicated that they ignored or were unaware of any existing rewards that were offered in return for sharing personal knowledge. Some participants felt that managers treated any shared knowledge as belonging them and this results in employees viewing their personal knowledge as a source of 'power' and preferring to keep it to themselves.

\section{Ill-formalized knowledge sharing processes and fragmented discourse}

The findings indicated that the participants found it difficult to share knowledge without formalized processes being in place. Formalized knowledge sharing processes ensure that the knowledge to be shared is updated and targeted as well as appropriately applied. Well-designed formalized processes were perceived as a safeguard mechanism for the organizations' 
intellectual capital. Even more, formalization in knowledge sharing was found to minimize risks of employees' ignorance about the recipients of the knowledge they share.

\section{Low quality training and false sense of awareness}

The survey participants clearly stated that the training materials provided did not meet the needs of all employees. In addition, they were not receiving adequate and appropriate training to make use of the available tools to share knowledge. In addition, they were not provided with suitable feedback or advice on how to share knowledge with their colleagues appropriately. The participants also indicated that the lack of appropriate training increases their ignorance, not only about how to share knowledge, but also what to share, when, and to whom. The majority of the participants also stated that due to the lack of the appropriate training, sharing was done on an ad-hoc basis, merely sharing what they had seen or heard from others, without thinking creatively and proposing innovative ways of doing business.

The underlying role of ignorance

The study findings supported those from Study 1 in showing that ignorance was affecting employees' motivation and ability to share knowledge, highlighting that the impact of CFFs on knowledge sharing effectiveness can be profound. Participants were found to be unaware of existing processes, available tools and perceptions of their immediate supervisors regarding the knowledge sharing process implemented by their organization. They were also found to not know how their personal knowledge would be treated by their immediate supervisors. Even more, given the tight time-constraints they experience to accomplish their daily tasks, employees were not able to determine whether they should devote time to knowledge sharing activities. Employees were also found to be unaware of the duration of the process itself, due to the lack of well-defined and formalized procedures. Moreover, it was evident that illinformed employees could lead to dysfunctional knowledge sharing scenarios, in that those 
who lack the knowledge of existing rewards and on-boarding schemes could negatively affect their productivity.

\subsubsection{Frequency of knowledge management tendencies}

The study results provided us with a rich set of data regarding how the participants make use of knowledge repositories. Specifically, the majority of the participants $(53,1 \%)$ stated that they make use of codified knowledge when organizing, chairing, or performing phase reviews. Among the sources of codified knowledge available to the participants, guides $(75,2 \%)$, handbooks $(61,6 \%)$ and templates $(49,3 \%)$ were seen to be the most used. Regarding the tendency of participants to acquire knowledge from the corporate site, only 7,5\% stated that they use intranet on a daily basis, while the majority of them, use the Intranet $(26,1 \%)$ on a monthly basis.

\subsubsection{Quantitative data}

The study findings supported some interesting and significant correlations between the singleitem self-report variables, which confirmed the impact of the aforementioned CFFs in the effectiveness of knowledge sharing practices (Table 2). Specifically, the findings revealed that employees' difficulty to find the necessary knowledge to accomplish their tasks (V8) negatively affects their perceptions regarding the applicability (V1) and the effectiveness (V2) of the existing organizational systems to share knowledge, as well as the formalization of the knowledge sharing process itself (V3).

Furthermore, the findings indicate that the antecedents of such difficulty (V8) in this setting, are the discouragement they perceive from their line manager to share knowledge with their colleagues (V4) as well as the lack of the sufficient opportunity that employees perceive, not only to share knowledge within their units (V5), but also to acquire new knowledge from their colleagues (V6). The lack of time employees often face (V7) is also another antecedent to their difficulty in finding valuable knowledge to perform their tasks effectively, along with 
the lack of the sufficient information about the knowledge materials to be shared (V9) and the availability of effective knowledge capture tools (V11).

The quality of training employees receive (V10) is found to strongly correlate with the effectiveness (V2) of the existing knowledge sharing systems, the formalization of the knowledge sharing process (V3), the lack of perceived line manager encouragement (V4), the opportunities employees are lacking to share knowledge with (V5) and acquire new knowledge from (V6) their colleagues. Among others, one condition that leads to the poor quality of training is the unavailability of sufficient knowledge capture tools (V11).

Finally, the quantitative data of this study confirmed that employee's ignorance regarding the established reward schema for those who share knowledge (V12) negatively affected employees' perceptions regarding the effectiveness of the existing knowledge infrastructure.

[Place Table 2 around here]

\section{Discussion}

Our study demonstrates that knowledge sharing effectiveness is greatly dependent on certain CFFs, which determine employee behaviors, perceptions and attitudes towards their willingness or unwillingness to participate in organizational knowledge sharing at all levels. In addition, organizational characteristics are also found to affect knowledge sharing effectiveness. These findings provide novel insights into why organizations fail to share knowledge and have implications for both theory and practice at organizational and individual levels.

\subsection{Implications for theory}

Past research has tended to focus on the need for organizations to increase knowledge capabilities in order to improve organizational performance (Skyrme and Amidon, 1997; Wong 
and Aspinwall, 2005). CFFs are vastly under discussed, as organizational capabilities tend to be more closely linked to successes. However, this can often be misleading, as success can be applied inconsistently, misused or misinterpreted, therefore restricting organizations from identifying causes of plausible failures (Chong, 2006). In this respect, a shift towards exploring reasons for failure should be seen as important and beneficial.

Drawing on previous studies of failure, and on the OS theory that organizational failures are the outcomes of managerial misbehaviors, we confirm CFFs impeding knowledge sharing with their roots in managerial action or inaction. Further, we expand on the CFFs originating in both lower-level employees' behaviors, attitudes and beliefs towards knowledge sharing, as well as those in relation to existing organizational characteristics. Such factors reflect current working processes, activities and actions, while exposing the weaknesses of not providing clear knowledge sharing goals, not encouraging employees to share the knowledge they possess and not appropriately training staff so that they can effectively participate in knowledge sharing processes. Table 3 presents a detailed assessment of the organizational and individual trajectories of CFFs, along with relevant theoretical underpinnings.

\section{[Place Table 3 around here]}

The landscape of the knowledge economy requires effective knowledge sharing and immediate implementation of new knowledge in day-to-day organizational operations (Davenport, 2001). In many cases, however, the sharing of new and existing knowledge is found to be an ambiguous process for employees. This might be because of knowledge diversity and unclear goals of what knowledge should be shared, to what extent and with whom. As Spender (2003, p. 266) notes “uncertainty, managers' frequent companion as they guide firms towards anticipated goals, is poorly dealt within theories of the firm. If knowledge is to be treated as the most strategic of assets, we must consider its relation to uncertainty". Our study findings confirm that those who interact within ill-defined knowledge frameworks, and 
are assigned to vague knowledge sharing tasks, may often cope with role ambiguity. Therefore, they experience detrimental employee attitudinal and behavioral outcomes, for instance, tension, anxiety, decreased job satisfaction and decreased productivity (e.g., Cohen, 1959; Kahn et al., 1964; Smith, 1957).

Employees who perceive that they receive benefits from others feel obliged and also reciprocate favorable outcomes in exchange (Blau, 1964; Gouldner, 1960). In this regard, "when the leader provides resources in a way that is perceived to be beneficial and equitable, the member will view the relationship positively" (Sluss et al., 2008, p. 458). In line with Lee et al. (2014), our study findings promote the importance of perceived encouragement by line managers as an important element when the knowledge sharing is processed. As such, employees can contribute to knowledge sharing effectiveness when perceiving encouragement from their managers, forming networks or undertaking initiatives to share knowledge as part of their jobs.

\subsection{Implications for practice}

Six key strategies have been created to help practitioners enhance knowledge sharing. Those focus on outcomes and provide a way forward for managing knowledge in organizations.

\section{Strategy \#1: Boost creativity through knowledge sharing}

The findings support the tendency of employees to make use of codified knowledge through various organizational repositories. Without underestimating its value, explicit knowledge is not as dynamic as tacit and, often, becomes easily obsolete (Smith, 2001). It is essential, therefore, to encourage employees to participate in networking opportunities "for engaging in sense-making conversations that raise good questions, challenge the status quo, and directly deal with ambiguity and equivocality" (Zack, 2000, p. 369). This can indeed help to discover what the organization truly knows, facilitating the opportunity to develop and continually advance (O’Dell and Grayson, 1998). 
Moreover, organizations should design more effective structures and redesign jobs, allowing employees the time needed to share and exchange personal knowledge with appropriate guidance. An optimal corporate governance structure, particularly within and between Communities of Practice (CoPs), could also improve knowledge sharing and provide the platform for efficient knowledge transactions (Hara and Hew, 2007). Nevertheless, attention should be paid to face-to-face interaction (along with the continual enhancement of technology), as well as to well-designed training programs, aiming at increasing employees' information literacy and critical thinking. These should not only be provided by experts in the specific field, but also by experienced employees, who possess the knowledge embedded in their organization.

\section{Strategy \#2: Enhance employee willingness to share knowledge}

In line with the extant literature, the study findings indicate that the process of knowledge sharing is time-consuming. Therefore, employees may not be incentivized or willing to share and generate new knowledge (Riege, 2005), due to the time pressure they often experience in having to accomplish their daily tasks effectively within time constraints. Effective knowledge sharing requires a supportive organizational environment that builds upon the principles of communication, trust and social networks (Dyer and Nobeoka, 2000). Continual enhancement of KMSs also enhances knowledge sharing intention (Dong et al., 2016). The establishment of such principles needs time and, therefore, organizations should devote time to share their knowledge efficiently and effectively. Organizations should allow employees time to get involved in knowledge sharing activities, instead of looking for more time-efficient alternatives on knowledge sharing. This could be achieved by more flexible and versatile organizational structures, enriched job descriptions, as well as encouraging KMS adoption (Dong et al., 2016). Strategy \#3: Combat task and role ambiguity 
The competitive and dynamic business environment increasingly requires employees to share knowledge with others (Chow and Chan, 2008; Davenport and Prusak, 1998; Drucker, 2002), either through formal or informal organizational processes (Cummings, 2004). Along the same lines, the effectiveness of knowledge sharing has been also shown in informal contexts (e.g., Gupta and Govindarajan, 2000; Reagans and McEvily, 2003; Tsai, 2002), as well as an unplanned behavior (Hsu et al., 2007). As shown in our study, non-formalized processes can mean employees have critical knowledge gaps. In particular, multiple processes used for the same or similar tasks can cause tension amongst staff members and initiate siloed behaviors with insufficient knowledge and poor awareness of the technology employed in the organization. In addition, the existence of poorly architected or overlapping KMSs used to share knowledge, which may often clash with one another, could also cause confusion and tension in employees, and may result in multiple dysfunctional situations for managers. Equally, the limits on usage of the internal KM website by staff members, as well as the uncoordinated introduction of a new tool suite for managing documents and archiving information, can also cause role ambiguity. Therefore, to achieve successful knowledge sharing outcomes we suggest that organizations should pay particular attention to a well-formalized process, while investing in a solid KM infrastructure.

\section{Strategy \#4: Build strong knowledge sharing capabilities}

Employee training has been widely investigated in relation to employees' personal and professional development, as well as organizations' profitability, growth and increased performance outcomes (Aguinis and Kurt, 2009). The study findings indicate that training cutbacks and the lack of high-quality training can hinder the effectiveness of knowledge sharing. Therefore, organizations should scrutinize their current training approaches to ensure they allow for the heterogeneous nature of their employee base, in terms of both job role and skillset (Choueke and Armstrong, 1998). As Jarvenpaa and Staples (2000) state, the sharing of 
ideas among employees is a key process underlying collective knowledge within an organization, without which a company may not be able to leverage its most valuable asset. “By upgrading employees' skills and knowledge, they are in a better position to produce highquality products and services in the most cost-effective way, adapt to change, and contribute to company competitiveness through product or process innovation" (Birdi et al., 2008, p. 471). As such, employees should be extensively trained so that they are confident in what they know and share with others. This will also help them better understand what they might not know, therefore harnessing emergent knowledge learning opportunities.

\section{Strategy \#5: Cultivate a knowledge sharing culture}

The study supports the positive relationship between time spent at the company and knowledge of reward mechanisms, which identifies issues with the on-boarding process and the sufficient induction into a knowledge sharing culture. This suggests a positive relationship between employees' willingness to share knowledge and expected rewards. In line with our findings, it is expected that rewards might positively affect knowledge sharing (e.g., Burgess, 2005; Yahya and Goh, 2002); hence, promotion of reward and recognition mechanisms can be embedded within an organization's strategy and form part of its culture.

Furthermore, high staff turnover and the recruitment of new talent can have the potential to affect employees' loyalty and corporate culture, while incurring significant costs related to loss of firm knowledge and experience (Quan and Cha, 2010). Additional funding is therefore required to mitigate risks such as low performance, poor decision-making and inefficient problem solving due to the potential lack of skills and support.

\section{Strategy \#6: Manage organizational ignorance}

One of the key outcomes derived from this study, and which does not appear to be extensively discussed in KM literature, is the importance of managing ignorance to help harness knowledge capabilities and avoid knowledge sharing deficient situations. Two main areas were evident in 
this context. Those include the limited knowledge of on-boarders, as well as the limited knowledge of employees of reward and recognition mechanisms in the organization. Organizations which take for granted that newcomers already know the best practices and knowledge culture, tend to implement poor induction programs and use weak communication channels. This can also have a further impact on employees, as ignoring the increased knowledge support needed for on-boarders may lead to multiple difficulties in performing daily operational tasks. Even more, this might also demotivate employees, creating an increased risk of staff considering leaving the organization.

These two factors highlight the importance of managing ignorance to avoid dysfunctional knowledge sharing scenarios. By recognizing, therefore, "the value and pervasiveness of ignorance in organizational contexts" (Roberts 2013, p. 232) as well as building on current research discussions around prompt recovery from situations of knowledge sharing loss, this paper suggests that ignorance can be seen as a means through which to uncover CFFs. In this context and based on the CFFs identified in this study, a number of different ways in which ignorance can be linked to several dysfunctional knowledge sharing scenarios have been further identified. Table 4 outlines this relationship between CFFs and organizational ignorance that our study has revealed.

[Place Table 4 around here]

\subsection{Limitations and implications for future research}

As common in all academic research, the study has limitations that can be addressed in future research. First, since our data was collected from the Aerospace and Defense industry, it is important to acknowledge that the study generalizability might be limited. Nevertheless, due to the exploratory nature of our work, our findings may reflect similar organizational settings with agile and less hierarchical structures, without rejecting their transferability (Denscombe, 2014). Future research, therefore, could investigate CFFs in other sectors by also taking into 
consideration other organizational characteristics such as the size of organizations, the organizational structure and the organization's maturity.

Second, a pertinent quantitative analysis could be performed to rank and prioritize the list of CFFs identified in this study, as well as further investigation into the moderating role of managing ignorance in improving knowledge sharing performance. There are also opportunities to test the mediating or moderating effects of other variables in the relationship between CFFs and knowledge sharing effectiveness, e.g., the role of a certain supportive leadership style, such as empowering leadership as a potential mediator or other characteristics such as organization tenure and organizational structure as moderating variables. Such an analysis should cover diverse industries operating globally within knowledge-intensive environments.

Third, although the thematic based findings of the qualitative study has led us to develop single-item self-report scales, future studies could develop multi-item variables to measure the effectiveness of KMS or expand on measures of knowledge sharing culture, employee intention to share knowledge as well as knowledge sharing personal attitudes and believes, e.g., the knowledge is power syndrome (Sarti, 2018).

Fourth, as the study presents linkages between knowledge sharing and organizational ignorance, further research could explore this bidirectional relationship by reconsidering other well-discussed high-performance practices, such as employee training and development. For instance, in contrast with our findings in this industry, there is some evidence to suggest that, during the previous two recessions, training cutbacks have been moderated by the pressure of regulatory requirements (Felstead and Green, 1994; Felstead et al., 2012). A potential avenue for future research in this area could explore why knowledge sharing appears to be treated as a 'soft touch' for cutbacks and question whether there is a need for a regulatory requirement for knowledge sharing in organizations today. 
Fifth, positioning other knowledge related phenomena, such as power relationships, knowledge obsolescence, as dependent or independent variables would provide a greater understanding of how these underlying failure attributes, qualities, and characteristics can reveal knowledge-poor, or otherwise ignorance-rich situations. Such research could be usefully tested via surveys, using constructs from the wider knowledge management literature. Last, given the importance of managing ignorance, the study results have significant implications for practitioners performing key roles in knowledge-intensive organizations as discussed in the preceding section.

\section{Concluding remarks}

This study has looked at why organizations fail to share knowledge. Through the identification of certain CFFs, the analysis provides insight into how managerial inactions, organizational characteristics, as well as employees' beliefs and perceptions, can act to inhibit knowledge sharing in the workplace. Acknowledging the existence of such factors, while preventing or eliminating their presence, can help organizations to achieve knowledge sharing effectiveness. The key role of organizational ignorance has also been highlighted to explore new ways of averting failure. Finally, this paper indicates new areas of opportunity for building efficient and effective knowledge sharing mechanisms, which are essential for both the short and long-term sustainability of organizations. 


\section{References}

Aguinis, H. and Kraiger, K. (2009), "Benefits of training and development for individuals and teams, organizations, and society", Annual Review of Psychology, Vol. 60, pp. 451474.

Akhavan, P. and Pezeshkan, A. (2014), "Knowledge management critical failure factors: a multi-case study". VINE: The Journal of Information and Knowledge Management Systems, Vol. 44 No. 1, pp. 22-41.

Alavi, M. and Leidner, D. (2001), "Knowledge management and knowledge management systems: conceptual foundations and research issues", MIS Quarterly, Vol. 1, pp. 107136.

Amankwah-Amoah, J. (2016), "An integrative process model of organisational failure". Journal of Business Research, Vol. 69 No. 9, pp. 3388-3397.

Argote, L. and Ingram, P. (2000), "Knowledge transfer: A basis for competitive advantage in firms", Organizational Behavior and Human Decision Processes, Vol. 82 No. 1, pp. 150-169.

Bakonyi, J. (2018), "Seeing Like Bureaucracies: Rearranging Knowledge and Ignorance in Somalia”, International Political Sociology, Vol. 12 No. 3, pp. 256-273.

Belassi, W. and Tukel, O.I. (1996), "A new framework for determining critical success/failure factors in projects”, International Journal of Project Management, Vol. 14 No. 3, pp.141-151.

Birdi, K., Clegg, C., Patterson, M., Robinson, A., Stride, C.B., Wall, T.D. and Wood, S.J. (2008), "The impact of human resource and operational management practices on company productivity: A longitudinal study", Personnel Psychology, Vol. 61 No. 3, pp. 467-501.

Blau, P.M. (1964), Exchange and Power in Social Life, John Wiley \& Sons, New York, NY.

Braganza, A. and Möllenkramer, G.J. (2002), "Anatomy of a failed knowledge management initiative: lessons from PharmaCorp's experiences", Knowledge and Process Management, Vol. 9 No. 1, pp. 23-33.

Burgess, D. (2005), "What Motivates Employees to Transfer Knowledge Outside Their Work Unit?”, Journal of Business Communication, Vol. 42 No. 4, pp. 324-348.

Cannon, M. and Edmondson, A. (2005), "Failing to Learn and Learning to Fail (Intelligently): How Great Organizations Put Failure to Work to Innovate and Improve", Long Range Planning, Vol. 38 No. 3, pp. 299-319.

Chia, R. and Holt, R. (2007), "Wisdom as learned ignorance", in Kessler, E. and Bailey, J. (Ed.), Handbook of Managerial and Organizational Wisdom, Sage, Thousand Oaks, CA, pp. 505-526.

Chong, S.C. (2006), "KM critical success factors: A comparison of perceived importance versus implementation in Malaysian ICT companies", The Learning Organization, Vol. 13 No 3, pp. 230-256.

Choueke, R. and Armstrong, R. (1998), "The learning organisation in small and mediumsized enterprises", International Journal of Entrepreneurial Behavior \& Research, Vol. 4 No. 2, pp. 129-140.

Chow, W.S. and Chan, L.S. (2008), "Social network, social trust and shared goals in organizational knowledge sharing", Information \& Management, Vol. 45 No. 7, pp. 458-465.

Chua, A. and Lam, W. (2005). "Why KM projects fail: a multi-case analysis". Journal of Knowledge Management, Vol. 9 No. 3, pp.6-17.

Cohen, R.A. (1959), "Situational structure, self esteem and threat-oriented reactions to power", in Cartwright, D. (Ed.), Studies in social power. Institute for Social Research, University of Michigan, Michigan. 
Connelly, C.E. and Kelloway, K.E. (2003), "Predictors of employees' perceptions of knowledge sharing cultures", Leadership \& Organization Development Journal, Vol. 24 No. 5, pp. 294-301.

Cummings, J.N. (2004), "Work groups, structural diversity, and knowledge sharing in a global organization", Management Science, Vol. 50 No. 3, pp. 352-364.

Dahlin, K.B., Weingart, L.R. and Hinds, P.J. (2005), "Team diversity and information use", Academy of Management Journal, Vol. 48 No. 6, pp. 1107-1123.

Darr, E.D., Argote, L. and Epple, D. (1995), "The acquisition, transfer, and depreciation of knowledge in service organizations: Productivity in franchises", Management Science, Vol. 41 No. 11, pp. 1750-1762.

Davenport, T., De Long, D. and Beers, M. (1998), "Successful knowledge management projects", Sloan Management Review, Vol. 39 No. 2, pp. 43-57.

Davenport, T. and Prusak, L. (1998), Working Knowledge: How Organizations Manage What They Know, Harvard Business School Press, Cambridge, MA.

Davenport, T. (2001), "Knowledge work and the future of management", in Bennis, W.G., Spreitzer, G.M. and Cummings, T.M. (Ed.), The future of leadership: Today's top leadership thinkers speak to tomorrow's leaders, Jossey-Bass, San Francisco, pp. 4158.

Denrell, J. (2003), "Vicarious learning, undersampling of failure, and the myths of management", Organization Science, Vol. 14 No. 3, pp. 227-243.

Denscombe, M. (2014), The good research guide for small-scale social research projects, Open University Press, Maidenhead.

Dong, T.P., Hung, C.L. and Cheng, N.C. (2016), "Enhancing knowledge sharing intention through the satisfactory context of continual service of knowledge management systems", Information Technology \& People, Vol. 29 No. 4, pp. 807-829.

Drucker, P. (2002), “The Discipline of Innovation”, Harvard Business Review, Vol. 80, pp. 95-104.

Du Plessis, M. (2007), “The role of knowledge management in innovation", Journal of Knowledge Management, Vol. 11 No. 4, pp. 20-29.

Dyer, J. H. and Nobeoka, K. (2000), "Creating and managing a high-performance knowledge-sharing network: The Toyota case”, Strategic Management Journal, Vol. 21 No. 3, pp. 345-367.

Edmondson, A.C. (2011), "Strategies for learning from failure". Harvard Business Review, 89(4), pp.48-55.

Felstead, A. and Green, F. (1994), “Training During the Recession”, Work Employment \& Society, Vol. 8 No. 2, pp. 199-219.

Felstead, A., Green, F. and Jewson, N. (2012), "An analysis of the impact of the 2008-9 recession on the provision of training in the UK", Work Employment \& Society, Vol. 26 No. 6, pp. 968-986.

Flowers, S. (1997), "Information systems failure: identifying the critical failure factors", Failure and Lessons Learned in Information Technology Management, Vol. 1 No. 1, pp. 19-29.

Fontaine, M. and Lesser, E. (2002), Challenges in managing organizational knowledge, IBM Corporation, Somers, NY.

Gallivan, M., Eynon, J. and Rai, A. (2003), “The challenge of knowledge management systems: Analyzing the dynamic processes underlying performance improvement initiatives", Information Technology \& People, Vol. 16 No. 3, pp. 326-352.

Ganesh, L. and Mehta, A. (2010). "Critical success factors for successful enterprise resource planning implementation at Indian SMEs". International Journal of Business, Management and Social Sciences, Vol. 1 No. 1, 65-78. 
Gouldner, A.W. (1960), "The norm of reciprocity: A preliminary statement", American Sociological Review, Vol. 25 No. 2, pp. 161-178.

Gross, M., and McGoey, L. (Eds.). (2015), Routledge International Handbook of Ignorance Studies. Taylor \& Francis, Basingstoke, England.

Gupta, A.K. and Govindarajan, V. (2000), "Knowledge flows within multinational corporations", Strategic Management Journal, Vol. 21 No. 4, pp. 473-496.

Schubmehl, D. and Vesset, D. (2014), The Knowledge Quotient: Unlocking the Hidden Value of Information Using Search and Content Analytics, IDC, Framingham, MA.

Hara, N. and Hew, K.F. (2007), "Knowledge-sharing in an online community of health-care professionals", Information Technology \& People, Vol. 20 No. 3, pp. 235-261.

Hardy, C., Phillips, N. and Lawrence, T.B. (2003), "Resources, knowledge and influence: The organizational effects of interorganizational collaboration", Journal of Management Studies, Vol. 40, No. 2, pp. 321-347.

Hsu, M.H., Ju, T.L., Yen, C.H. and Chang, C.M. (2007), "Knowledge sharing behavior in virtual communities: The relationship between trust, self-efficacy, and outcome expectations", International Journal of Human-Computer Studies, Vol. 65 No. 2, pp. 153-169.

Israilidis, J., Siachou, E., Cooke, L. and Lock, R. (2015), "Individual variables with an impact on knowledge sharing: The critical role of employees' ignorance", Journal of Knowledge Management, Vol. 19 No. 6, pp. 1109-1123.

Jarvenpaa, S.L. and Staples, D.S. (2000), "The use of collaborative electronic media for information sharing: an exploratory study of determinants". The Journal of Strategic Information Systems, Vol. 9 No. 2-3, pp. 129-154.

Jafari, M., Akhavan, P., Nour, J.R., and Fesharaki, M. (2007). "Knowledge management in Iran aerospace industries". Aircraft Engineering and Aerospace Technology: An International Journal, Vol. 79 No. 4, pp. 375-389.

Kahn, R.L., Wolfe, D.M., Quinn, R.P., Snoek, J.D. and Rosenthal, R.A. (1964), Organizational stress: Studies in role conflict and ambiguity, John Wiley, Oxford, England.

Laureani, A. and Antony, J. (2012), "Standards for Lean Six Sigma certification", International Journal of Productivity and Performance Management, Vol. 61 No. 1, pp. 110-120.

Lee, J., Lee, H. and Park, J.G. (2014), "Exploring the impact of empowering leadership on knowledge sharing, absorptive capacity and team performance in IT service", Information Technology \& People, Vol. 27 No. 3, pp. 366-386.

Madsen, P. M. and Desai, V. (2010), "Failing to learn? The effects of failure and success on organizational learning in the global orbital launch vehicle industry", Academy of Management Journal, Vol. 53 No. 3, pp. 451-476.

Malhotra, Y. (2004), "Why Knowledge Management Systems Fail? Enablers and Constraints of Knowledge Management in Human Enterprises", in Koenig, M. and Srikantaiah, K. (Ed.), Knowledge Management Lessons Learned: What Works and What Doesn't, Information Today, Medford, NJ, pp. 87-112.

Mellahi, K., Jackson, P. and Sparks, L. (2002). "An exploratory study into failure in successful organizations: The case of Marks \& Spencer", British Journal of Management, 13(1), pp.15-29.

Mellahi, K. and Wilkinson, A. (2004), "Organizational failure: a critique of recent research and a proposed integrative framework". International Journal of Management Reviews, Vol. 5 No. 1, pp. 21-41.

Mellahi, K. (2005), "The dynamics of boards of directors in failing organizations", Long Range Planning, 38(3), pp.261-279. 
Miles, M.B. and Huberman, A.M. (1994), Qualitative Data Analysis, Sage Publications, Thousand Oaks, CA.

Nonaka, I. and Takeuchi, H. (1995), The Knowledge-Creating Company: How Japanese Companies Create the Dynamics of Innovation, Oxford University Press, New York, NY.

O'Dell, C. and Grayson, C.J. (1998), "If only we knew what we know: Identification and transfer of internal best practices". California Management Review, Vol. 40 No. 3, pp. 154-174.

Patton, M.Q. (2002), Qualitative Research and Evaluation Methods, Sage, Thousand Oaks, CA.

Peters, T. (1987), Thriving on Chaos, Guild, London.

Pinelli, T., Barclay, R., Kennedy, J. and Bishop, A. (1997), Knowledge diffusion in the U.S. aerospace industry: managing knowledge for competitive advantage, Ablex Publishing Corporation, Greenwich, CT.

Quan, J. and Cha, H. (2010), "IT certifications, outsourcing and information systems personnel turnover", Information Technology \& People, Vol. 23 No. 4, pp. 330-351.

Riege, A. (2005), "Three-dozen knowledge-sharing barriers managers must consider", Journal of Knowledge Management, Vol. 9 No. 3, pp. 18-35.

Reagans, R. and McEvily, B. (2003), "Network structure and knowledge transfer: the effects of cohesion and range", Administrative Science Quarterly, Vol. 48 No. 2, pp. 240-267.

Roberts, J. (2013), "Organizational ignorance: Towards a managerial perspective on the unknown", Management Learning, Vol. 44 No. 3, pp. 215-236.

Sarti, D. (2018), "Organizational tenure and knowledge-sharing behaviours", Journal of Workplace Learning, Vol. 30, pp. 291-307.

Schein, E.H. (1987), Process Consultation, Addison-Wesley, Reading, MA.

Sitkin, S.B. (1992), "Learning through failure: The strategy of small losses", Research in Organizational Behavior, Vol. 14, pp. 231-266.

Skyrme, D. and Amidon, D. (1997), “The knowledge agenda", Journal of Knowledge Management, Vol. 1 No. 1, pp. 27-37.

Sluss, D.M., Klimchak, M. and Holmes, J.J. (2008), "Perceived organizational support as a mediator between relational exchange and organizational identification", Journal of Vocational Behavior, Vol. 73 No. 3, pp. 457-464.

Smith, E.E. (1957), "The effects of clear and unclear role expectations on group productivity and defensiveness", Journal of Abnormal and Social Psychology, Vol. 55 No. 2, pp. 213-217.

Smith, E.A. (2001). The role of tacit and explicit knowledge in the workplace. Journal of Knowledge Management, Vol. 5 No. 4, pp.311-321.

Spender, J.C. (2003), "Exploring uncertainty and emotion in the knowledge-based theory of the firm", Information Technology \& People, Vol. 16 No. 3, pp. 266-288.

Starbuck, W. H., Greve, A. and Hedberg, B.L.T (1978). "Responding to Crisis", Journal of Business Administration, Vol. 9 No. 2, pp. 111-137.

Storey, J. and Barnett, E. (2000), "Knowledge management initiatives: learning from failure", Journal of Knowledge Management, Vol.4 No. 2, pp. 145-156.

Stuart, I., McCutcheon, D., Handfield, R., McLachlin, R. and Samson, D. (2002), "Effective case research in operations management: A process perspective", Journal of Operations Management, Vol. 20 No. 5, pp. 419-433.

Tashakkori, A. and Teddlie, C. (1998), Mixed methodology: Combining qualitative and quantitative approaches. Sage, London.

Taussig, M.T. (1999), "Defacement: Public secrecy and the labor of the negative". Stanford University Press, Stanford, CA. 
Tax, S.S. and Brown, S.W. (1998), "Recovering and learning from service failures", Sloan Management Review, Vol. 40 No. 1, pp. 75-89.

Tooranloo, H.S., Ayatollah, A.S., and Alboghobish, S. (2018), "Evaluating knowledge management failure factors using intuitionistic fuzzy FMEA approach". Knowledge and Information Systems, Vol. 57 No. 1, pp. 183-205.

Tsai, W. (2001), "Knowledge transfer in intraorganizational networks: Effects of network position and absorptive capacity on business unit innovation and performance", Academy of Management Journal, Vol. 44 No. 5, pp. 996-1004.

Tsai, W. (2002), "Social structure of "coopetition" within a multiunit organization: Coordination, competition, and intraorganizational knowledge sharing", Organization Science, Vol. 13 No. 2, pp. 179-190.

UK Department for Business, Energy and Industrial Strategy (2018), Aerospace Sector Deal, policy paper.

Voss, C., Tsikriktsis, N. and Frohlich, M. (2002), "Case research in operations management", International Journal of Operations \& Production Management, Vol. 22 No. 2, pp. 195-219.

Watson, M.D. and Griffin, M.D. (2014), "Communication and Knowledge Management in Elegant System Design”, paper presented at AIAA Space 2014: Complex Aerospace System Engineering (CASE), 4-7 August, San Diego, CA.

Wong, K.Y. and Aspinwall, E. (2005), "An empirical study of the important factors for knowledge-management adoption in the SME sector", Journal of Knowledge Management, Vol. 9 No. 3, pp. 64-82.

Weber, M. (1947), Theory of Social and Economic Organization, Free Press, New York.

Yahya, S. and Goh, W.K. (2002), "Managing human resources toward achieving knowledge management", Journal of Knowledge Management, Vol. 6 No. 5, pp. 457-468.

Yeo, K.T. (2002). "Critical failure factors in information system projects”. International Journal of Project Management, Vol. 20 No. 3, pp. 241-246.

Yin, R. (2003), Case Study Research: Design and Methods, Sage, Thousand Oaks, CA.

Zack, M. (2000), "Managing Organizational Ignorance", in Cortada, J. and Woods, J. (Ed.), The Knowledge Management Yearbook 2000-2001, Butterworth-Heinemann, Woburn, MA, pp. 353-373. 


\section{Appendices}

Table 1: Qualitative data from Study 2

\begin{tabular}{|c|c|}
\hline $\begin{array}{l}\text { CFFs and associated } \\
\text { challenges }\end{array}$ & Illustrative quotes for CFFs \\
\hline $\begin{array}{l}\text { Staff churn and closed } \\
\text { mindset }\end{array}$ & $\begin{array}{l}\text { "Availability of others to shares, clarity of the information shared. Out of date information"; "Inconsistencies with correct knowledge \& } \\
\text { Diluted / tainted 3rd or 4th generation knowledge sharing"; "Perception of bespoke needs result in people not believing they need to share", } \\
\text { "You have the slight possibility to swamp people with information and create greater indecision"; "People aren't seen as 'specialized' or } \\
\text { 'knowledgeable' if they share all their knowledge, therefore may not like appearing of 'equal status' to others (of less experience, younger, } \\
\text { more junior in the org", "Too many people with input, not agree on things"; "Stifle intellectual independence / critical thinking. Total } \\
\text { knowledge is not just knowing the answer; but experiencing the journey to derive the answer"; "Experience can be taken out of context and } \\
\text { mis-applied"; "Too many people with opinions rather than hard facts"; "Knowledge can become outdated and obsolete - it can sometimes } \\
\text { be difficult to identify a knowledge owner with up to date information"; "Can be a bit overwhelming at times?". }\end{array}$ \\
\hline $\begin{array}{l}\text { Limited time availability } \\
\text { and the averseness to } \\
\text { share knowledge }\end{array}$ & $\begin{array}{l}\text { "Time find the appropriate information"; "It takes time to establish links. Time pressure on task which limit sharing"; "Can use up a lot of } \\
\text { time with little immediate visible benefit. Detracts from the milestone achievement upon which we all as individuals are measured"; "Takes } \\
\text { time away from primary duties"; "Virtually impossible to capture return on investment for time spend knowledge sharing. Difficult to define } \\
\text { what knowledge sharing is and what it encompasses"; "Could be a lot of time for minimal gain. Often needed when there is minimal time to } \\
\text { do it"; "There is a perception it costs time and money and does not repay the business.........shame as this is a most short sighted view"; } \\
\text { "The time it can take to get one bit of information that you need"; "End up doing other people's jobs and spend so much time } \\
\text { sharing/coaching with no recognition that you have your own milestones to meet"; "It takes a great deal of time to capture knowledge in the } \\
\text { written form"; "Having the time to do it effectively is difficult"; "Added pressure on time / distraction from priority work"; "The time } \\
\text { required is not always recognized and made available - it's often seen as a diversion activity rather than a value-adding one"; "People don't } \\
\text { always take the time to confirm relevance"; "Time allowed within 'business as usual' daily tasks to seek and share experiences \& } \\
\text { knowledge"; "Requires an investment of time"; "Takes too much time from own work"; "Too much time talking and not enough time } \\
\text { doing"; "Too much at times. Not enough time to attend forums"; "Finding the time to share and the appropriate medium for sharing"; } \\
\text { "Sometimes difficult and time consuming to find the needed information"; "Time consuming if the rationale for the sharing is not clear". }\end{array}$ \\
\hline $\begin{array}{l}\text { Unclear knowledge } \\
\text { sharing goals and task } \\
\text { ambiguity }\end{array}$ & $\begin{array}{l}\text { "Sometimes knowledge obtained from different sources can be conflicting"; "Inconsistency"; "Fragmentation and consistency"; "You don't } \\
\text { know what you should know or what you're missing from the knowledge transfer"; "Misinterpretation and the danger of thinking you know } \\
\text { more that you do (both directions)"; "Little, although information overload can be a problem"; "If knowledge is passed on incorrectly or is } \\
\text { misunderstood and used in the wrong way"; "Potential to dilute the message if what has been shared is not validated"; "Inaccurate facts } \\
\text { perpetuated"; "Need to be sure that the knowledge is relevant and accurate"; "Sometimes it's only people views that are shared"; "Possible } \\
\text { distraction with other goals"; "Sharing knowledge can improve processes etc but can lead to debates where no better way forward is } \\
\text { agreed"; "Becoming distracted with knowledge that is not pertinent to your day to tasks and objectives"; "Ill-informed comment being taken } \\
\text { as fact"; "We are good in broadcasting but bad in receiving. People don't share exactly what has happened in a project"; "Usually the } \\
\text { hardest thing about FAQ or other knowledge sharing strategies is sorting through the volume to find what is applicable to your case". }\end{array}$ \\
\hline $\begin{array}{l}\text { Lack of perceived } \\
\text { encouragement and the }\end{array}$ & $\begin{array}{l}\text { "Taking focus from your core task, you need money to do it"; "Everybody wants it to happen, but it always takes second place to other } \\
\text { panics so we don't do it when we should. People need to believe in it and not think the cost of doing it is wasteful"; "Knowledge sharing } \\
\text { should be a two-way street. Somebody has to want it. You have to tailor it to meet the individual's needs"; "There are no real mechanisms for }\end{array}$ \\
\hline
\end{tabular}




\section{feeling of being}

disenfranchised

\section{Ill-formalized knowledge}

sharing processes and

fragmented discourse rewarding any knowledge sharing. I already do work for parts of [the organization] other than my business line, and I am effectively doing this work out the goodness of my heart". "Little or no credit is given to source"; "Takes time, viewed by management as possible waste of time and lack of task focus"; "Managers/Business Leaders who then claim knowledge as their own"; "Others take credit for my knowledge and work"; "Information gets distorted and other people take the credit for the information"; "Most people do not do it"; "Can be forced to share for sharing's sake"; "Competition sensitivity, security, export issues"; "Possible wasted time".

"Interpreted and used incorrectly"; "It is difficult to formalize"; "Too much fluff around the knowledge clogs up communication bandwidth. Lack of logical organization dilutes knowledge into information, data, and opinion at times"; "The assumption that all "good practice" is universally applicable"; "Inappropriate use our application of the knowledge by individuals that do not have a full understanding of the consequences"; "No downside to sharing, only on trying to institutionalize a process that people come to rely upon more than the knowledge itself"; "The administrative effort to ensure that documents which have been shared are kept up to date"; "Passing on a nonstandard practice"; "Is it vetted (i.e. is the knowledge correct or are you getting bad data)? Hard to find the right data at the right time (too much or not enough)"; "Getting the entire enterprise to use a knowledge system. So, unless there is robust roll-out plan, knowledge sharing systems are worthless"; "If the shared knowledge becomes fragmented or incomplete, the recipient may proceed under assumptions that turn out not to be true (for example, sharing a drawing package for a design so it can be built to print but not also sharing the fact that it has safety hazards requiring training to control)"; "The downside is the potential to share information, which should not be shared; for example, when tools may make certain knowledge widely available when it should have been very limited"; "Sharing knowledge is good however the best practices have to be captured properly and integrated centrally"; "We need a better way to track and share lessons learned. There is very little downside to sharing knowledge other than it might be misunderstood if it is just in a quick written form (i.e., always good to see if actual person / group with the knowledge can be available when needed for details)". "Too much info sharing can cause confusion. Info needs to be managed effectively"; "Not enough suitable tools to do so quickly and to a large enough audience"; "There are no downsides to sharing knowledge. The challenge is having a mechanism for capturing and disseminating knowledge to the right people".

Low quality training and "Inconsistent advice"; "Inconsistent feedback"; "Few - the issue is about sorting the noise from the gems and then sharing it"; "People do not get used to think innovative way. They prefer usually to copy and use others knowledge instead of being creative by themselves"; "Loss of control of the usage of the material and lack of feedback"; "When people use the shared knowledge badly or not at all"; "If it's right everyone gets it right, However If it's bad practice, then everyone gets it wrong"; "Plagiarism, people not realising who thought of it first": "Risk of consuming resources sharing outside appropriate audience". 
Table 2: Descriptive statistics and correlations

\begin{tabular}{|c|c|c|c|c|c|c|c|c|c|c|c|c|}
\hline & V1 & $\mathrm{V} 2$ & $\mathrm{~V} 3$ & V4 & V5 & V6 & V7 & V8 & V9 & V10 & V11 & V12 \\
\hline $\begin{array}{l}\text { Knowledge Sharing systems are well-applied } \\
\text { within my units (V1) }\end{array}$ & 1 & & & & & & & & & & & \\
\hline Knowledge Sharing systems are effective (V2) & $.509^{* *}$ & 1 & & & & & & & & & & \\
\hline $\begin{array}{l}\text { There are not well-formalized systems to share } \\
\text { knowledge with my colleagues (V3) }\end{array}$ & $.169^{* *}$ & $.132^{*}$ & 1 & & & & & & & & & \\
\hline $\begin{array}{l}\text { I am not encouraged to share knowledge by my } \\
\text { supervisor (V4) }\end{array}$ & $.124^{*}$ & $.132^{*}$ & $.449^{* *}$ & 1 & & & & & & & & \\
\hline $\begin{array}{l}\text { I am not given sufficient opportunity to share } \\
\text { knowledge with my colleagues (V5) }\end{array}$ & $.146^{* *}$ & $.147^{* *}$ & $.548^{* *}$ & $.402^{* *}$ & 1 & & & & & & & \\
\hline $\begin{array}{l}\text { I am not given sufficient opportunity to acquire } \\
\text { knowledge from my colleagues (V6) }\end{array}$ & $.207^{* *}$ & $.204^{* *}$ & $.518^{* *}$ & $.430^{* *}$ & $.672^{* *}$ & 1 & & & & & & \\
\hline $\begin{array}{l}\text { I am not given enough time to share knowledge } \\
\text { (V7) }\end{array}$ & $.106^{*}$ & .080 & $.428^{* *}$ & $.402^{* *}$ & $.473^{* *}$ & $.517^{* *}$ & 1 & & & & & \\
\hline $\begin{array}{l}\text { In general, it is difficult to find the knowledge } \\
\text { required to do my job (V8) }\end{array}$ & $-.155^{* *}$ & $-.166^{* *}$ & $-.229^{* *}$ & $-.161^{* * *}$ & $-.253^{* *}$ & $-.307^{* *}$ & $-.212^{* *}$ & 1 & & & & \\
\hline $\begin{array}{l}\text { I am not provided with sufficient information } \\
\text { about the available knowledge materials to be } \\
\text { shared (V9) }\end{array}$ & $.169^{* *}$ & .080 & $.170^{* *}$ & $.252^{* *}$ & $.193^{* *}$ & $.220^{* *}$ & $.172^{* *}$ & $-.261^{* *}$ & 1 & & & \\
\hline $\begin{array}{l}\text { I don't perceive quality in the training I am } \\
\text { provided with (V10) }\end{array}$ & $-.131^{*}$ & -.085 & $-.225^{* *}$ & $-.242^{* *}$ & $-.195^{* *}$ & $-.185^{* *}$ & $-.165^{* *}$ & $.227^{* *}$ & $-.614^{* *}$ & 1 & & \\
\hline $\begin{array}{l}\text { There are not sufficient knowledge capture tools } \\
\text { available within my unit (V11) }\end{array}$ & .072 & .033 & $.339^{* *}$ & $.202^{* *}$ & $.305^{* *}$ & $.261^{* *}$ & $.227^{* *}$ & $-.165^{* *}$ & $.126^{*}$ & $-.108^{*}$ & 1 & \\
\hline $\begin{array}{l}\text { I am not aware of the rewards provided to } \\
\text { employees who share knowledge (V12) }\end{array}$ & -.066 & $-.164^{* *}$ & .029 & -.044 & -.041 & -.076 & -.019 & .019 & -.022 & -.002 & .011 & 1 \\
\hline
\end{tabular}

Note. ${ }^{*} \mathrm{p} \leq .05, * * \mathrm{p} \leq .01$. 
Table 3: Identification, implications and comparison of critical factors

\begin{tabular}{|c|c|c|c|}
\hline CFFs & Organizational trajectories & Individual trajectories & Sample of related theoretical paradigms \\
\hline Staff churn & $\begin{array}{l}\text { Project disruption; decreased innovative capacity; } \\
\text { competitive disadvantage for the business. }\end{array}$ & $\begin{array}{l}\text { Employees may not be able to follow up work } \\
\text { produced by their predecessors; the worker } \\
\text { population is likely to contain a high percentage of } \\
\text { novice; ill-informed and demotivated workers. }\end{array}$ & $\begin{array}{l}\text { e.g., Wong and Aspinwall (2005); Yahya and } \\
\text { Goh (2002) }\end{array}$ \\
\hline $\begin{array}{l}\text { Limited time } \\
\text { availability }\end{array}$ & $\begin{array}{l}\text { Decrease of the intensification of social capital; } \\
\text { making the organization vulnerable to threats that } \\
\text { jeopardize the growth and quality of important } \\
\text { knowledge. }\end{array}$ & $\begin{array}{l}\text { Poor relationship management between internal } \\
\text { teams and external partners. }\end{array}$ & $\begin{array}{l}\text { e.g., Riege (2005); Wong and Aspinwall } \\
\text { (2005) }\end{array}$ \\
\hline $\begin{array}{l}\text { Unclear knowledge- } \\
\text { sharing goals }\end{array}$ & $\begin{array}{l}\text { Inefficient work practices, lack of perspective; } \\
\text { incorrect decision-making; critical decisions may be } \\
\text { delayed unnecessarily. }\end{array}$ & $\begin{array}{l}\text { No added incentive for employees to work more } \\
\text { efficiently and effectively; limited awareness of } \\
\text { lessons learned; employees may feel that feeding } \\
\text { into KM activities is not part of their job. }\end{array}$ & $\begin{array}{l}\text { e.g., Cohen (1959); Kahn et al. (1964); O’Dell } \\
\text { and Grayson (1998); Smith (1957) }\end{array}$ \\
\hline $\begin{array}{l}\text { Lack of perceived } \\
\text { encouragement }\end{array}$ & $\begin{array}{l}\text { Tacit knowledge may not be circulated effectively } \\
\text { across the organization; interest in new projects may } \\
\text { be lost. }\end{array}$ & $\begin{array}{l}\text { Although employees may feel more confident with } \\
\text { the knowledge they possess, they could often see it } \\
\text { as a personal rather than a collective possession. }\end{array}$ & $\begin{array}{l}\text { e.g., Akhavan and Pezeshkan (2014); } \\
\text { Davenport } \text { et al. (1998); Skyrme and Amidon } \\
\text { (1997); Yahya and Goh (2002) }\end{array}$ \\
\hline $\begin{array}{l}\text { Ill-formalized } \\
\text { knowledge sharing } \\
\text { processes }\end{array}$ & $\begin{array}{l}\text { Patchy and inconsistent application of KM initiatives; } \\
\text { disconnected priorities; inefficiency and missed } \\
\text { opportunities; additional costs are likely to occur as a } \\
\text { result of inefficient or ineffective processes. }\end{array}$ & $\begin{array}{l}\text { Employees may be confused as to which method or } \\
\text { tool to use to do their job; internal tensions may } \\
\text { appear. }\end{array}$ & $\begin{array}{l}\text { e.g., Chow and Chan (2008); Cummings } \\
\text { (2004); Davenport and Prusak (1998); Drucker } \\
\text { (2002); Gupta and Govindarajan (2000); Hsu } \\
\text { et al. (2007); Reagans and McEvily (2003); } \\
\text { Tsai (2002) }\end{array}$ \\
\hline Low quality training & $\begin{array}{l}\text { The organizational memory fades gradually } \\
\text { becoming less accurate; lack of creativity and } \\
\text { innovation due to the lack of new knowledge in the } \\
\text { organization. }\end{array}$ & $\begin{array}{l}\text { Employees become ignorant of both internal project } \\
\text { requirements as well as new ways to improve } \\
\text { efficiency and effectiveness (best practice); may not } \\
\text { be able to produce new products and services in } \\
\text { order to fulfil the demands of the clients. }\end{array}$ & $\begin{array}{l}\text { e.g., Aguinis and Kurt (2009); Riege (2005); } \\
\text { Yahya and Goh (2002) }\end{array}$ \\
\hline
\end{tabular}


Table 4: The ramifications of ignorance in dysfunctional knowledge sharing situations

\section{CFFs \\ Association to ignorance ramifications}

Staff churn: Loss of experienced talent may lead to illinformed behaviours and inefficient working practices

due to the inability to share knowledge appropriately.

Limited time availability: Employees have difficulty in

identifying and selecting relevant information and KM

materials due to the absence of appropriate time.

Unclear knowledge sharing goals: Employees

perceived lack of acknowledgment and understanding of

the unknowns due to the absence of interpersonal communication with their supervisors

Lack of perceived encouragement: Employees are

unable to support organizational goals and produce

valuable outputs due to the lack of knowledge,

managerial direction, time and resources available to

them.

Ill-formalized knowledge sharing processes: Non well-

defined and formalized knowledge sharing mechanisms

(e.g., knowledge networks and KM documentation) may

not increase the value of knowledge to an organization.

Low quality training: Employees have difficulty in

identifying and selecting relevant information and

appropriate KM materials.
Industries employing an aging workforce are lacking personal

motivation to explore new ways of doing business and share the knowledge they possess with others

When employees feel the pressure to accomplish routine tasks

and complete activities within tight time-constraints,

habitually do not share the knowledge they possess.

When organizations lack appropriate communication channels employees appear to be unaware of knowledge sharing goals and how they should act.

When employees are not encouraged to share their knowledge, they are isolated and ill-informed.

When knowledge networks and other knowledge sharing mechanisms are not appropriately managed, overall levels of organizational ignorance may be increased.

Employees seek to increase their knowledge through learning and development. Low quality training as well as training

cutbacks can be a breeding ground for ignorance-rich behaviors.

\section{Practical implications}

Organizations should place veteran employees to consult and provide with training and coaching newcomers rather than performing operational roles.

Leadership should design more effective structures and redesign jobs allowing employees the time needed to share and exchange knowledge with appropriate guidance.

Face-to-face interaction (as opposed to technology alone) reduces employees' unknowns and, therefore,

organizational ignorance.

An optimal corporate governance structure, particularly within and between CoPs, could improve knowledge sharing and provide the platform for efficient knowledge

transaction.

Leadership plays a vital role in developing knowledge sharing networks, working efficiently and helping to solve organizational issues.

Well-designed training programs aiming at increasing employees' information literacy and critical thinking provided by experts and veteran employees who possess key knowledge embedded in the organization. 